\title{
INTRODUCTION
}

The period prevalence of postpartum depression among women is a striking $21.9 \%$ the first year after birth, which makes it one of the most common medical complications of childbearing (Gaynes et al. 2005). Sertraline has been identified as an antidepressant of choice for breastfeeding women because infants are unlikely to develop quantifiable serum sertraline levels and very few adverse events associated with sertraline have been reported (Weissman et al. 2004). However, some women choose either to forego medication or discontinue breastfeeding during pharmacotherapy to eliminate any risk from medication exposure to their infant. Decisions regarding antidepressant use during breastfeeding must include not only considerations for the risks of medication exposure to infants and/or maternal side effects, but also the risks of untreated depression and formula feeding (US Department of Health and Human Services 2011). In this paper, we examine the risk-benefit profile of sertraline treatment during breastfeeding, summarize the available literature on its use, present previously unpublished data, and perform a correlation-based meta-analysis of sertraline serum levels in mother-infant pairs.

\section{Benefits of Breastfeeding}

Breastfeeding confers numerous benefits on maternal and infant health in addition to having positive economic impact (Bartick \& Reinhold 2010; Bartick et al. 2013). In recognition of mounting evidence of the public health impact of breastfeeding, the U.S. Department of Health and Human Services released "The Surgeon General's Call to Action to Support Breastfeeding," which proclaimed breastfeeding as a national priority in 2011 (US Department of Health and Human Services 2011). Breastmilk provides an optimal source of nutrition for infants. It offers immunological and antioxidant protection and is associated with a reduced likelihood of various diseases, including asthma, diarrhea, ear infections, 
pneumonia and sudden infant death syndrome (Ip et al. 2007). Children who breastfeed for more than one month have a lower risk of becoming overweight, and this effect increases with increasing duration of breastfeeding (Harder et al. 2005). Breastfeeding also confers advantages for maternal health such as decreased risk for breast and ovarian cancers, hypertension, and type II diabetes mellitus (Ip et al. 2007; McClure et al. 2012; Schwarz et al. 2010; Stuebe et al. 2011). Breastfeeding women experience greater weight loss postpartum than those who opt to use formula (US Department of Health and Human Services 2011). With the myriad benefits afforded by breastfeeding, a decision to provide a strictly formula-based diet to avoid exposure to maternal medication should be made only after a careful risk-benefit analysis.

\section{Risks of Untreated Postpartum Depression}

Women with postpartum depression may experience thoughts of self-harm, and suicide is responsible for up to $20 \%$ of maternal deaths in the first year after delivery (Lindahl et al. 2005; Wisner et al. 2013). The negative effects of maternal depression on children include an increased risk for impaired mental and motor development, difficult temperament, poor self-regulation, low self-esteem, and behavior problems (Murray et al. 2003). Infants exposed to irregular maternal patterns of communication, such as withdrawn and unresponsive or hostile and intrusive behaviors, demonstrate increased avoidance and distress (Conroy et al. 2012; Field 1998; Tronick \& Weinberg 1997). Previous studies suggest that postpartum depression negatively impacts children's cognitive and behavioral development (Conroy et al. 2012; Grace et al. 2003). Children exposed to postpartum depression demonstrate reduced peer social competence, and lower school adjustment than non-exposed children (Kersten-Alvarez et al. 2012). These adversities persist beyond early childhood, and Verbeek et al. (2012) found postpartum depression to be significantly associated with internalizing problems during adolescence.

\section{Sertraline and Breastfeeding}

In 2001 the American Academy of Pediatrics (AAP) categorized the effects of psychoactive drugs on nursing infants as "unknown but may be of concern" (American Academy of Pediatrics Committee on Drugs 2001). Despite the emergence of additional data since this 2001 statement, the 2013 AAP statement still cautions that infants may be exposed to clinically significant levels (defined as $\geq 10 \%$ of maternal serum concentration), and the long-term effects of exposure remain unknown (Sachs et al. 2013). Little information is available in the literature regarding growth and development of infants exposed to sertraline solely during breastfeeding. Hackett et al. (2006) provide a case report of a breastfed infant whose mother was taking $300 \mathrm{mg}$ sertraline and $8 \mathrm{mg}$ reboxetine daily. This infant achieved normal weight for age milestones at 2.1 months and a Denver developmental age as a percentage of actual age of $119 \%$. Hendrick et al. (2003) report a sample of 78 women who initiated SSRI or SNRI antidepressant either during pregnancy or within four weeks postpartum, 25 of whom were taking sertraline. Women breastfed exclusively through month four and at least $50 \%$ through month six. Weights for these infants at six months did not differ significantly from normative weights of six-month-old breastfed infants. 
Research investigating the impact of antidepressant use in breastfeeding infants is of interest worldwide. The Australian Adverse Drug Reaction Advisory Committee received two reports of side effects possibly related to sertraline exposure via breastmilk. A four-monthold infant experienced benign neonatal sleep myoclonus (Mammen et al. 1997), and a fivemonth-old infant reportedly had agitation that spontaneously resolved (Rohan \& Symonston 1997). The two cases from the Australian Adverse Drug Reaction Advisory Committee did not include infant serum sertraline concentrations. Without quantification of exposure to the infants, it is difficult to assess the potential for symptom association with sertraline exposure. Hendrick et al. (2001) found a strong negative correlation between infant age and serum levels, although other studies have not reported this correlation. Muller et al. (2013) reported a case of possible serotonergic overstimulation in a preterm infant after exposure to sertraline via breastmilk. However, this infant, in addition to being preterm, was exposed to sertraline in utero, where the magnitude of exposure is much greater (Kim et al. 2006).

Though serum concentrations are typically not quantifiable in breastfed infants of mothers taking sertraline, the question remains whether even very low exposure impacts infant development. Capello et al. (2011) evaluated both serum sertraline levels and serotonin transporter occupancy in rat pups with lactational exposure to five antidepressants, including sertraline, and found evidence of central nervous system (CNS) exposure even when serum concentrations were undetectable. Epperson et al. (1997) evaluated platelet 5-

hydroxytryptamine levels in four breastfeeding mother-infant dyads before and after maternal exposure to sertraline. While the authors noted changes in maternal platelet levels following sertraline initiation, they did not observe any change in infant platelet levels, which suggests little to no central reuptake inhibition.

For breastfeeding women, a salient question is the impact of sertraline on breastmilk production and breastfeeding success. Nebhinani (2013) reports 3 cases of sertraline associated galactorrhea in nonpregnant, non-nursing women. Hyperprolactinemia is another rare side effect of SSRIs, including sertraline (Ashton \& Longdon 2007), although sertraline does not confer additional risk above that observed with other SSRIs or SNRIs (Trenque et al. 2011). Holland (2000) described six women who reported decreased milk supply while taking sertraline in the absence of a comparison group. The milk supply resolved with an increase in fluid intake and frequency of feedings. In a small, prospective study of eight women using SSRIs, including one woman taking sertraline, an average delay of 16.7 hours for the onset of milk secretory activation was described relative to women who were not on an SSRI (Marshall et al. 2010). This study did not include depressed women who were not taking an SSRI; therefore, the delay could be related to either the SSRI or the underlying depression. By four days postpartum, however, there was no statistically significant difference between groups in percentage of mothers experiencing feeding difficulties.

\section{Sertraline in Breastfed Infants}

A number of factors impact the passage of a drug into breastmilk, including protein binding, absorption rate, half-life, peak serum time, $\mathrm{pH}$, dissociation constant, volume of distribution, molecular size, degree of ionization, and solubility (Breitzka et al. 1997). Protein binding, in particular, has a significant impact on passage of drugs into breastmilk, where highly protein 
bound drugs are less likely to be transferred into breastmilk. Sertraline is $98 \%$ bound to plasma proteins, thereby reducing the likelihood of transfer (De Vane et al. 2002). In adults, sertraline reaches maximum plasma concentrations between four and eight hours following oral administration and has a half-life of 13-45 hours with a mean of approximately 26 hours (De Vane et al. 2002). Because sertraline has a large volume of distribution, much of the drug in the body is outside systemic circulation. Sertraline's primary metabolite, Ndesmethylsertraline, has a longer half-life than sertraline and is moderately pharmacologically active in in vivo models, with approximately $5-10 \%$ of the potency of sertraline in inhibition of serotonin uptake (De Vane et al. 2002).

The infant's ability to absorb, detoxify, and excrete the drug determines the serum concentration. Investigators have examined infant cytochrome P450 genotype to assess impact on drug metabolism. Berle et al. (2004) determined serum sertraline levels and CYP2D6/CYP2C19 genotypes in six mother-infant pairs. Sertraline was not detected in the serum of any of the drug-exposed infants. Sertraline is metabolized predominantly by CYP2B6 with lesser contributions from CYP2C19, CYP2C9, CYP3A4, and CYP2D6, and these multiple metabolic pathways improve the likelihood of effective drug metabolism in both mothers and infants, which reinforces the view of sertraline as a good choice for breastfeeding (Obach et al. 2005). The sample presented by Berle et al. (2004) also included a paroxetine-treated poor metabolizer mother-infant pair, which in theory confers the highest likelihood for the development of substantial serum drug concentrations, and the infant did not have detectable serum SSRI levels. This supports the contention by both Weissman et al. (2004) and Lanza di Scalea et al. (2009) that routine serum level testing and/or genotyping is not recommended for breastfeeding women who take SSRI antidepressants.

\section{METHODS}

\section{Analysis of Current Literature}

Given the varied methodology and small sample sizes in the available literature, we sought to examine the direction and strength of association between maternal and infant sertraline levels via secondary research based on a literature review of existing studies. We conducted a search of PubMed using the following keywords: "sertraline", "breastfeeding", "infant serum", and "antidepressants." We also consulted the National Library of Medicine LactMed entry for "sertraline". We identified 13 studies that reported 142 sertraline levels for breastfed infants whose mothers were taking sertraline (Altshuler et al. 1995; Berle et al. 2004; Birnbaum et al. 1999; Dodd 2001; Epperson et al. 2001; Hendrick et al. 2001; Kristensen et al. 1998; Mammen et al. 1997; Stowe et al. 2003; Stowe et al. 1997; Sunder et al. 2004; Weissman et al. 2004; Wisner et al. 1998). Of these 142, 123 (86.6\%) reported sertraline concentrations below the limit of detection specified for each manuscript. The median of the remaining values was $5 \mathrm{ng} / \mathrm{mL}$. Wisner, Perel, and Blumer (Wisner et al. 1998) reported one infant with a serum sertraline level of $64 \mathrm{ng} / \mathrm{mL}$, which the authors indicate may have been a result of the mother giving sertraline directly to the asymptomatic infant. Stowe et al. (2003) report one infant with a sertraline level of $87 \mathrm{ng} / \mathrm{mL}$, which was higher than the corresponding maternal serum concentrations. This infant concurrently received albuterol treatments, inhaled steroids, and hydroxyzine, and the authors 
hypothesize that the elevated levels may be a result of an interaction effect among the multiple medications. Of note, these two infants with serum sertraline levels similar to treated adults did not demonstrate any health complications as a result of these sertraline levels.

Of the 13 studies reporting sertraline concentrations, 11 also reported concentrations for the less active metabolite desmethylsertraline. In all these reports, infant $\mathrm{N}$-desmethylsertraline levels were higher than infant sertraline levels. Of the 125 levels 84 (67.2\%) were below the limit of detection specified for each manuscript. The median of the remaining values was 5 $\mathrm{ng} / \mathrm{mL}$. Sunder et al. (2004) report an additional 7 infants with desmethylsertraline levels below $12 \mathrm{ng} / \mathrm{mL}$, though individual infant levels are not specified. The same aforementioned infants who presented with elevated sertraline levels (Stowe et al. 2003; Wisner et al. 1998) also presented with highly elevated $\mathrm{N}$-desmethylsertraline levels, and no adverse events were reported (De Vane et al. 2002).

In addition to the published data discussed above, we examined previously unpublished data from studies conducted by Katherine L. Wisner, M.D., M.S. and her research team at the University of Pittsburgh. These data include serum sertraline and desmethylsertraline levels for 25 mother-infant pairs (Table 1). Of these 25 mother-infant dyads, 23 (92.0\%) had sertraline levels below the $2 \mathrm{ng} / \mathrm{mL}$ limit of assay detection and all were less than 2.5 $\mathrm{ng} / \mathrm{mL} .21(84.0 \%)$ of the $25 \mathrm{~N}$-desmethylsertraline levels were non-detectable, and all were less than $5 \mathrm{ng} / \mathrm{mL}$. No adverse events were reported. A total of 167 concentrations from sertraline-exposed infants were available, with no reported adverse events.

Of the studies available in the literature the largest sample size is 29 mother-infant dyads (Hendrick et al. 2001). Small sample sizes coupled with measurement and methodological differences necessitate the need to apply a meta-analytic approach to optimally investigate the relationship between maternal and infant sertraline levels in breastfeeding dyads. In an effort to draw broader conclusions we synthesized the current literature and included unpublished data through a meta-analytic approach. To examine the role of publication status on the study findings, we used a moderation test. The use of meta-analyses allows for inclusion of unpublished studies to counter the file drawer effect phenomenon that is often present in our field.

\section{Meta-Analysis}

We conducted a meta-analysis using the Comprehensive Meta Analysis software (Borenstein et al. 2005). Of the 13 studies mentioned above, we included six in the metaanalysis. Studies were excluded if they did not provide specific values for individual mother-infant dyads, as this precluded the possibility of including the data in our correlation analysis, or if the number of mother-infant dyads with individual levels specified was less than four, as Comprehensive Meta-Analysis cannot perform computations with sample sizes this small. We also included the unpublished data from Table 1 (resulting in a total $\mathrm{N}=121$ mother-infant dyads). Weissman et al. (2004) included six dyads from one of Dr. Wisner's previously unpublished studies; consequently, we excluded these data from Table 1. 
In cases where the same mother-infant dyad had serum sertraline levels obtained more than once over the course of a study, we included only the earliest level obtained in our metaanalysis. This is a conservative approach, as some studies have suggested a negative correlation between infant age and serum levels. For the purpose of analysis, we also set any infant serum levels that were reported as "nondetectable" or "below limit of detection" to the limit of detection specified in each individual study. Where authors presented specific levels that were below the limit of detection, we substituted the value of the limit of detection specified in the manuscript. As these levels may have been anywhere from $0 \mathrm{ng} / \mathrm{ml}$ to the limit of detection in each study (most commonly $2 \mathrm{ng} / \mathrm{mL}$ ), analyzing these values as though they are as high as the limit of detection again represents a conservative approach.

We did not include dose in the meta-analysis because, due to high variability in metabolism of pharmaceuticals, we deemed maternal serum sertraline concentration a better indicator of the potential infant exposure. A random effects model was used to assess correlation between maternal and infant sertraline levels. The random effects model was chosen due to an assumption of high variability across studies in the time of sample collection, protocol design, and laboratories performing the sertraline analysis. Pearson product-moment correlation coefficients were calculated using sertraline levels in mothers and sertraline levels in infants. All Pearson-moment correlations were based within the same mother-baby dyad. Effect sizes were computed using product-moment correlation coefficients with corrections using Fisher's $Z_{\mathrm{r}}$-transformation (Hedges \& Olkin 1985). For ease of interpretation, each $Z_{\mathrm{r}}$ transformed correlation or mean correlation can be transformed back into standard (Pearson) correlation using the inverse of $Z_{\mathrm{r}}$ transformation. Additionally, each transformed $Z_{\mathrm{r}}$ value was corrected for sampling error using the inverse variance weight. A 95\% confidence interval was calculated for each effect size to establish whether it was statistically different from zero. Forest plots were used to detect outliers and to examine the distribution of effect sizes. The $\mathrm{Q}$ test of homogeneity was used to examine variation in effect sizes, and an $\mathrm{I}^{2}$ estimate was used to determine the degree of heterogeneity. To determine the presence of publication bias, funnel plots for a random effects model of sample size vs. effect size were used.

We examined the capacity of the following moderators to explain the variability in effect sizes between the studies: (1) sertraline use during pregnancy or only postpartum; (2) infant age at serum sampling (3) breastfeeding exclusively or partially (formula supplementation); and (4) publication status. Infant age was treated as a categorical variable dichotomized to ssix weeks versus >six weeks. Breastfeeding was quantified as a dichotomous variable fully breastfeeding vs. not fully breastfeeding. Some authors reported breastfeeding as a percentage while others reported number of feedings per day. Dyads were classified as fully breastfeeding if the percentage was $100 \%$ or the number of feedings per day was greater than six. For the publication status analysis, data from Weismann et al. (2004) was reported as unpublished in the original paper; therefore, we treated it as such and coded it as unpublished in our analysis. 


\section{RESULTS}

Table 3 shows results of the product-moment correlation estimates between maternal and infant serum sertraline levels, as well as the results of the four moderator analyses (use of sertraline in pregnancy vs. postpartum only, infant age, breastfeeding status, and publication status). The mean correlation depicting the relationship between maternal and infant sertraline concentrations in mother-baby dyads was small and not significant [Fisher's $\mathrm{Z}=0.048, \mathrm{p}=0.639,95 \% \mathrm{CI}(-0.154,0.251)]$ with confidence intervals including zero. Heterogeneity between studies was not significant, $\mathrm{Q}(8)=4.501, \mathrm{p}=0.809, \mathrm{IM}^{2}=0.000$. The funnel plot indicated no publication bias. Because sertraline has significantly higher metabolic activity than desmethylsertraline, we were particularly interested in moderator effects for sertraline and present these analyses in Table 3. Analyses of moderators identified in this study did not demonstrate significance for any of the moderator variables, which suggests that the relationship between mother and infant sertraline concentrations may not be significantly influenced by variables such as mother's use of sertraline during pregnancy vs. postpartum only, infant age, or full vs. partial breastfeeding. Additionally, publication status (published vs. unpublished) did not play a role in further explaining this relationship.

Maternal and infant desmethylsertraline levels were significantly correlated in these studies [Fisher's Z $=0.391, \mathrm{p}=0.017,95 \% \mathrm{CI}(0.071,0.711)$ ] and zero was not included in the confidence interval. Heterogeneity between studies was significant $Q(8)=17.034, p=$ $0.030, \mathrm{I}^{2}=53.036$, which indicates that the magnitude of the effect varies among studies included in this analysis.

The sum of sertraline and desmethylsertraline was significantly correlated between mothers and infants in these studies [Fisher's $\mathrm{Z}=0.367, \mathrm{p}=0.012,95 \% \mathrm{CI}(0.080,0.654)$ ] and zero was not included in the confidence interval. Heterogeneity between studies was not significant $\mathrm{Q}(8)=13.877, \mathrm{p}=0.085, \mathrm{I}^{2}=42.351$.

\section{DISCUSSION}

Effect size estimates showed no significant relationship between maternal and infant serum sertraline concentrations, which is consistent with low to non-detectable infant serum levels independent of the magnitude of maternal sertraline levels. This relationship was not impacted by pregnancy status when the sertraline was initiated, infant age, or level of breastfeeding. The correlation analysis revealed a significant relationship between maternal and infant serum desmethylsertraline concentrations, but this metabolite has only a fraction of the activity of sertraline. While Capello et al. (2011) observed serotonin transporter binding in animals exposed through breastmilk in the absence of detectable parent compounds, the absolute levels of desmethylsertraline in the exisiting literature are low and no adverse effects definitively linked to exposure through breastmilk have been reported. A significant relationship was also found for the sum of sertraline and desmethylsertraline, which stems primarily from the contribution of desmethylsertraline. 
These findings further reinforce endorsement of sertraline as a first-line antidepressant choice for breastfeeding women. The data also support that the dosing should be targeted to induce remission of depression rather than prescribing low doses to reduce infant exposure through breastmilk. In a previous study, we found that the following sertraline doses were associated with remission in 25 sertraline-treated women in a randomized clinical trial: $1=$ less than $100 \mathrm{mg} / \mathrm{d}, 12=100 \mathrm{mg} / \mathrm{d}, 5=125$ or $150 \mathrm{mg} / \mathrm{d}$, and $7=200 \mathrm{mg} / \mathrm{d}$ (Wisner et al. 2007).

\section{Limitations and Strengths}

Sample size, both within studies and in terms of the number of studies available in the literature, was a limitation in conducting this meta-analysis. We only deemed nine studies as adequate for inclusion, and of these nine studies, six reported sample sizes of 11 or fewer mother-infant dyads. The largest study sample size available included 29 dyads (Hendrick et al. 2001).

Within the moderator analyses, sample size was further limited when dividing individual study data into subgroups, particularly because the Comprehensive Meta Analysis software does not permit analyses when studies have a small sample size $(n<4)$.

Additionally, we noted substantial variability of methodology employed across studies. We observed variations in phlebotomy methods, and a variety of laboratories performed the serum sample assays. Most studies did not account for the timing of the mother's sertraline dose relative to the time of last infant feeding or blood draw. Given the pharmacokinetic characteristics of sertraline, with peak serum levels typically observed between six and eight hours following dose (De Vane et al. 2002) and peak breast milk levels observed in hind milk eight to nine hours following dose (Stowe et al. 2003), this information was relevant to the analyses performed. Milk production is also variable, so the concentration of sertraline in breast milk represents an average over several hours (Suri et al. 2002).

We further note a limitation in analysis due to a lack of consistency among the variables different researchers chose to report and the manner in which the researchers measured these variables. Across the nine studies included in the meta-analysis, infant age, infant adjusted age, infant weight at draw, infant weight at birth, infant gender, and breastfeeding frequency were included in some, but not all, studies. Some researchers presented breastfeeding amount as a percentage of total feedings while others reported the number of times daily a mother engaged in breastfeeding. These limitations underscore the need for methodological standardization in both variables reported and the manner in which researchers measure them.

In spite of these limitations, the findings further understanding of the safety profile of sertraline use during breastfeeding. To the best of the authors' knowledge, this meta-analysis constitutes the largest collection of currently available data on sertraline serum levels in mother-infant dyads. The synthesis of the available literature is an important contribution to clinical care for mothers and infants. 


\section{CONCLUSIONS}

When considering antidepressant use for breastfeeding women there is no "zero risk" option and consideration of the risks and benefits inherent in any course of action is necessary to make appropriate treatment choices. Sertraline is a first-line drug for breastfeeding women, due to documented low levels of exposure in breastfeeding infants and the very low number of adverse events described in case reports. Other antidepressants are also reasonable choices for use in breastfeeding women if they have had a positive response (for review, see (Berle \& Spigset 2011)). Based on the current literature, neither routine serum sampling nor genotyping is warranted for mothers taking sertraline while breastfeeding and/or their infants. Routine pediatric care is appropriate monitoring for the infants of women who breastfeed and take sertraline monotherapy.

\section{REFERENCES}

Altshuler LL, Burt VK, McMullen M, Hendrick V. Breastfeeding and sertraline: a 24-hour analysis. Journal of Clinical Psychiatry. 1995

American Academy of Pediatrics Committee on Drugs. Transfer of drugs and other chemicals into human milk. Pediatrics. 2001; 108:776. [PubMed: 11533352]

Ashton A, Longdon M. Hyperprolactinemia and galactorrhea induced by serotonin and norepinephrine reuptake inhibiting antidepressants. American Journal of Psychiatry. 2007; 164:1121-1122. [PubMed: 17606668]

Bartick M, Reinhold A. The burden of suboptimal breastfeeding in the United States: a pediatric cost analysis. Pediatrics. 2010; 125:e1048-e1056. [PubMed: 20368314]

Bartick MC, Stuebe AM, Schwarz EB, Luongo C, Reinhold AG, Foster EM. Cost analysis of maternal disease associated with suboptimal breastfeeding. Obstetrics \& Gynecology. 2013; 122:111-119. [PubMed: 23743465]

Berle JO, Spigset O. Antidepressant Use During Breastfeeding. Curr Womens Health Rev. 2011; 7:28-34. [PubMed: 22299006]

Berle JØ, Steen VM, Aamo TO, Breilid H, Zahlsen K, Spigset O. Breastfeeding during maternal antidepressant treatment with serotonin reuptake inhibitors: infant exposure, clinical symptoms, and cytochrome p450 genotypes. Journal of Clinical Psychiatry. 2004; 65:1228-1234. [PubMed: 15367050]

Birnbaum CS, Cohen LS, Bailey JW, Grush LR, Robertson LM, Stowe ZN. Serum concentrations of antidepressants and benzodiazepines in nursing infants: a case series. Pediatrics. 1999; 104:e11e11. [PubMed: 10390297]

Borenstein M, Hedges L, Higgins J, Rothstein H. Comprehensive meta-analysis version 2. Englewood, NJ: Biostat. 2005:104-104.

Breitzka RL, Sandritter TL, Hatzopoulos FK. Principles of drug transfer into breast milk and drug disposition in the nursing infant. Journal of human lactation: official journal of International Lactation Consultant Association. 1997; 13:155-158. [PubMed: 9233209]

Capello CF, Bourke CH, Ritchie JC, Stowe ZN, Newport DJ, Nemeroff A, Owens MJ. Serotonin transporter occupancy in rats exposed to serotonin reuptake inhibitors in utero or via breast milk. Journal of Pharmacology and Experimental Therapeutics. 2011; 339:275-285. [PubMed: 21775476]

Conroy S, Pariante CM, Marks MN, Davies HA, Farrelly S, Schacht R, Moran P. Maternal psychopathology and infant development at 18 months: the impact of maternal personality disorder and depression. Journal of the American Academy of Child \& Adolescent Psychiatry. 2012; 51:51-61. [PubMed: 22176939]

De Vane CL, Liston HL, Markowitz JS. Clinical pharmacokinetics of sertraline. Clinical Pharmacokinetics. 2002; 41:1247-1266. [PubMed: 12452737] 
Dodd S. Sertraline analysis in the plasma of breast-fed infants. Australian and New Zealand Journal of Psychiatry. 2001; 35:545-546. [PubMed: 11531744]

Epperson CN, Anderson GM, McDougle CJ. Sertraline and breast-feeding. New England Journal of Medicine. 1997; 336:1189-1190. [PubMed: 9102576]

Epperson N, Czarkowski KA, Ward-Oâ D, Weiss E, Gueorguieva R, Jatlow P, Anderson GM. Maternal sertraline treatment and serotonin transport in breast-feeding mother-infant pairs. American Journal of Psychiatry. 2001; 158:1631-1637. [PubMed: 11578995]

Field T. Maternal depression effects on infants and early interventions. Preventive Medicine. 1998; 27:200-203. [PubMed: 9578995]

Gaynes BN, Gavin N, Meltzer-Brody S, Lohr KN, Swinson T, Gartlehner G, Brody S, Miller WC. Perinatal depression: prevalence, screening accuracy, and screening outcomes: summary. 2005

Grace SL, Evindar A, Stewart D. The effect of postpartum depression on child cognitive development and behavior: a review and critical analysis of the literature. Archives of Women's Mental Health. 2003; 6:263-274.

Hackett LP, Ilett KF, Rampono J, Kristensen JH, Kohan R. Transfer of reboxetine into breastmilk, its plasma concentrations and lack of adverse effects in the breastfed infant. European Journal of Clinical Pharmacology. 2006; 62:633-638. [PubMed: 16699799]

Harder T, Bergmann R, Kallischnigg G, Plagemann A. Duration of breastfeeding and risk of overweight: a meta-analysis. American Journal of Epidemiology. 2005; 162:397-403. [PubMed: 16076830]

Hedges, L.; Olkin, I. Statistical methods for meta \{analysis. Academic Press; Orlando (Flor.); 1985.

Hendrick V, Fukuchi A, Altshuler L, Widawski M, Wertheimer A, Brunhuber MV. Use of sertraline, paroxetine and fluvoxamine by nursing women. The British Journal of Psychiatry. 2001; 179:163166. [PubMed: 11483479]

Hendrick V, Smith LM, Hwang S, Altshuler LL, Haynes D. Weight gain in breastfed infants of mothers taking antidepressant medications. Journal of Clinical Psychiatry. 2003; 64:410-412. [PubMed: 12716242]

Holland D. An observation of the effect of sertraline on breast milk supply. Australasian Psychiatry. 2000; 34:1032-1032.

Ip S, Chung M, Raman G. Tufts-New England Medical Center Evidence-based Practice Center. Breastfeeding and maternal and infant health outcomes in developed countries. Evid Rep Technol Assess (Full Rep). 2007; 153:1-186. [PubMed: 17764214]

Kersten-Alvarez LE, Hosman CM, Riksen-Walraven JM, van Doesum KT, Smeekens S, Hoefnagels C. Early school outcomes for children of postpartum depressed mothers: comparison with a community sample. Child Psychiatry \& Human Development. 2012; 43:201-218. [PubMed: 22011810]

Kim J, Riggs KW, Misri S, Kent N, Oberlander TF, Grunau RE, Fitzgerald C, Rurak DW. Stereoselective disposition of fluoxetine and norfluoxetine during pregnancy and breast-feeding. British Journal of Clinical Pharmacology. 2006; 61:155-163. [PubMed: 16433870]

Kristensen J, Ilett K, Dusci L, Hackett L, Yapp P, Wojnar-Horton R, Roberts M, Paech M. Distribution and excretion of sertraline and $\mathrm{N}$-desmethylsertraline in human milk. British Journal of Clinical Pharmacology. 1998; 45:453-458. [PubMed: 9643617]

Lanza di Scalea T, Wisner KL. Antidepressant medication use during breastfeeding. Clinical Obstetrics and Gynecology. 2009; 52:483. [PubMed: 19661763]

Lindahl V, Pearson JL, Colpe L. Prevalence of suicidality during pregnancy and the postpartum. Archives of Women's Mental Health. 2005; 8:77-87.

Mammen OK, Perel JM, Rudolph G, Foglia JP, Wheeler SB. Sertraline and norsertraline levels in three breastfed infants. Journal of Clinical Psychiatry. 1997; 58:100-103. [PubMed: 9108810]

Marshall AM, Nommsen-Rivers LA, Hernandez LL, Dewey KG, Chantry CJ, Gregerson KA, Horseman ND. Serotonin transport and metabolism in the mammary gland modulates secretory activation and involution. The Journal of Clinical Endocrinology \& Metabolism. 2010; 95:837846. [PubMed: 19965920] 
McClure CK, Catov JM, Ness RB, Schwarz EB. Lactation and maternal subclinical cardiovascular disease among premenopausal women. American Journal of Obstetrics and Gynecology. 2012; 207:46, e41-e46, e48. [PubMed: 22727348]

Müller MJ, Preuß C, Paul T, Streit F, Brandhorst G, Seeliger S. Serotonergic Overstimulation in a Preterm Infant After Sertraline Intake via Breastmilk. Breastfeeding Medicine. 2013; 8:327-329. [PubMed: 23249132]

Murray L, Cooper PJ, Wilson A, Romaniuk H. Controlled trial of the short-and long-term effect of psychological treatment of post-partum depression 2. Impact on the mother-child relationship and child outcome. The British Journal of Psychiatry. 2003; 182:420-427. [PubMed: 12724245]

Nebhinani N. Sertraline-induced galactorrhea: case report and review of cases reported with other SSRIs. General Hospital Psychiatry. 2013; 35:576, e573-e576, e575.

Obach RS, Cox LM, Tremaine LM. Sertraline is metabolized by multiple cytochrome P450 enzymes, monoamine oxidases, and glucuronyl transferases in human: an in vitro study. Drug Metabolism and Disposition. 2005; 33:262-270. [PubMed: 15547048]

Rohan A, Symonston A. Drug distribution in human milk. Aust Prescriber. 1997; 20:84.

Sachs HC, Frattarelli DA, Galinkin JL, Green TP, Johnson T, Neville K, Paul IM, Van den Anker J. The transfer of drugs and therapeutics into human breast milk: an update on selected topics. Pediatrics. 2013; 132:e796-e809. [PubMed: 23979084]

Schwarz EB, Brown JS, Creasman JM, Stuebe A, McClure CK, Van Den Eeden SK, Thom D. Lactation and maternal risk of type 2 diabetes: a population-based study. The American journal of medicine. 2010; 123:863, e861-e863, e866. [PubMed: 20800156]

Stowe ZN, Hostetter AL, Owens MJ, Ritchie JC, Sternberg K, Cohen LS, Nemeroff CB. The Pharmacokinetics of Sertraline Excretion into Human Breast Milk: Determinants of Infant Serum Concentrations. Journal of Clinical Psychiatry. 2003; 64:73-80. [PubMed: 12590627]

Stowe ZN, Owens M, Landry JC, Kilts CD, Ely T, Llewellyn A, Nemeroff CB. Sertraline and desmethylsertraline in human breast milk and nursing infants. American Journal of Psychiatry. 1997; 154:1255-1260. [PubMed: 9286185]

Stuebe AM, Schwarz EB, Grewen K, Rich-Edwards JW, Michels KB, Foster EM, Curhan G, Forman J. Duration of lactation and incidence of maternal hypertension: a longitudinal cohort study. American Journal of Epidemiology. 2011; 174:1147-1158. [PubMed: 21997568]

Sunder KR, Wisner KL, Hanusa BH, Perel JM. Postpartum depression recurrence versus discontinuation syndrome: observations from a randomized controlled trial. Journal of Clinical Psychiatry. 2004; 65:1266-1268. [PubMed: 15367055]

Suri R, Stowe ZN, Hendrick V, Hostetter A, Widawski M, Altshuler LL. Estimates of nursing infant daily dose of fluoxetine through breast milk. Biological Psychiatry. 2002; 52:446-451. [PubMed: 12242061]

Trenque T, Herlem E, Auriche P, Dramé M. Serotonin Reuptake Inhibitors and Hyperprolactinaemia. Drug Safety. 2011; 34:1161-1166. [PubMed: 22077504]

Tronick EZ, Weinberg MK. Depressed mothers and infants: failure to form dyadic states of consciousness. 1997

US Department of Health and Human Services. The Surgeon General's call to action to support breastfeeding. 2011.

Verbeek T, Bockting CL, van Pampus MG, Ormel J, Meijer JL, Hartman CA, Burger H. Postpartum depression predicts offspring mental health problems in adolescence independently of parental lifetime psychopathology. Journal of Affective Disorders. 2012; 136:948-954. [PubMed: 21930302]

Weissman AM, Levy BT, Hartz AJ, Bentler S, Donohue M, Ellingrod VL, Wisner KL. Pooled analysis of antidepressant levels in lactating mothers, breast milk, and nursing infants. American Journal of Psychiatry. 2004; 161:1066-1078. [PubMed: 15169695]

Wisner KL, Perel JM, Blumer J. Serum sertraline and N-desmethylsertraline levels in breast-feeding mother-infant pairs. American Journal of Psychiatry. 1998; 155:690-692. [PubMed: 9585724]

Wisner KL, Sit DK, Hanusa BH, Moses-Kolko EL, Perel JM. Reply to Drs Henderson and Vale. Journal of Clinical Psychopharmacology. 2007; 27:322-325. 
Wisner KL, Sit DK, McShea MC, Rizzo DM, Zoretich RA, Hughes CL, Eng HF, Luther JF, Wisniewski SR, Costantino ML. Onset timing, thoughts of self-harm, and diagnoses in postpartum women with screen-positive depression findings. JAMA Psychiatry. 2013; 70:490-498. [PubMed: 23487258] 
Pinheiro et al.

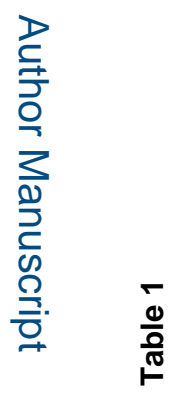

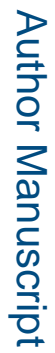

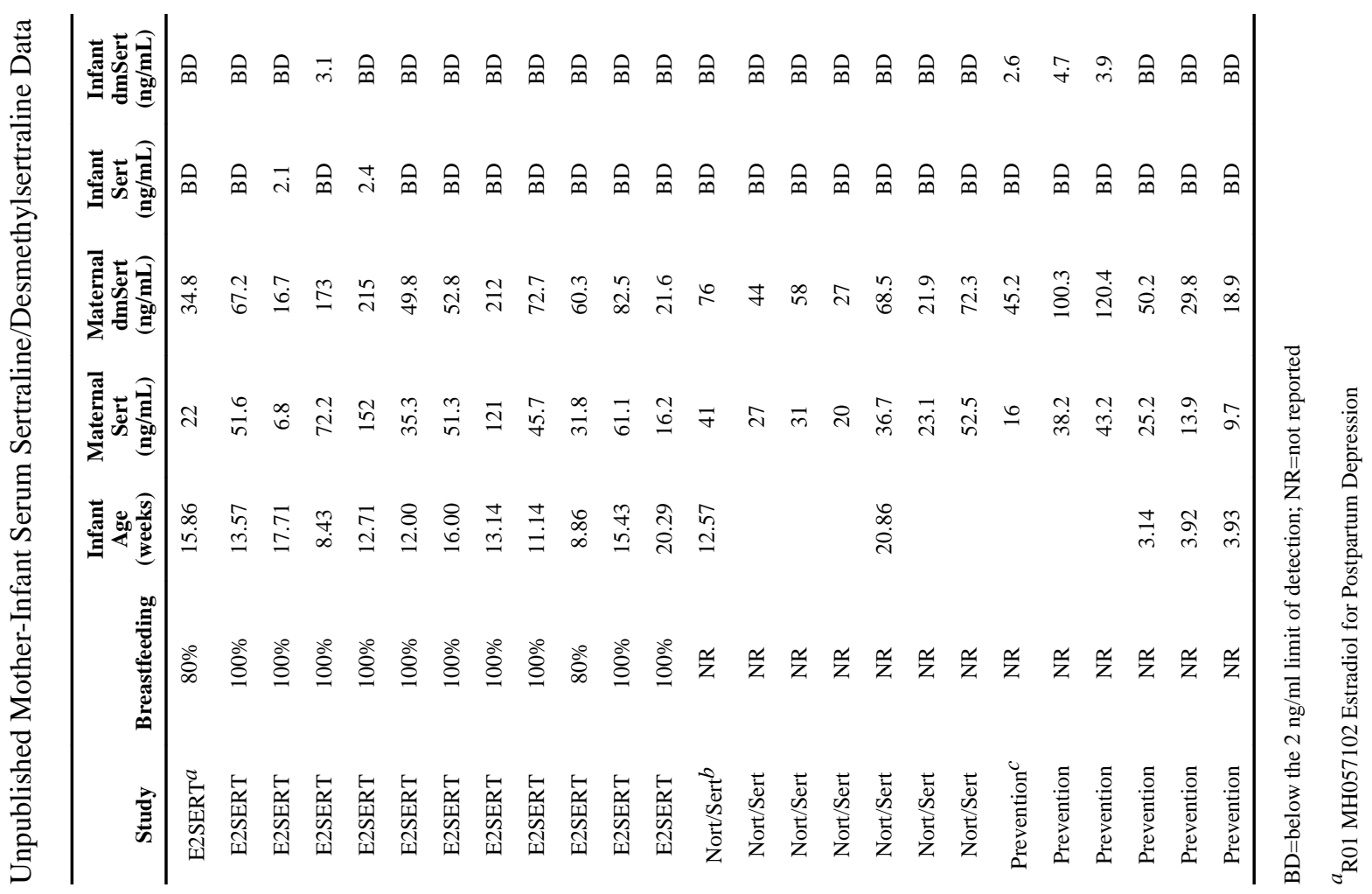

Arch Womens Ment Health. Author manuscript; available in PMC 2016 April 01. 


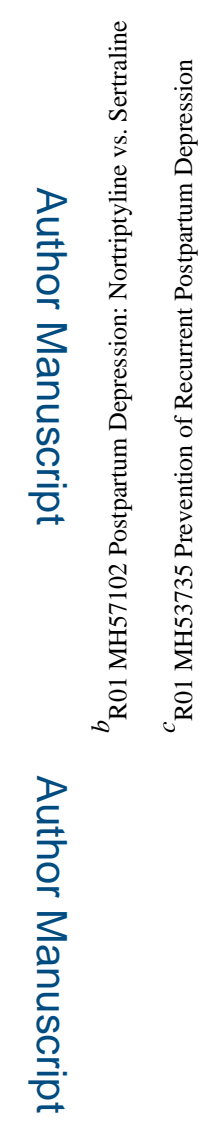

로을

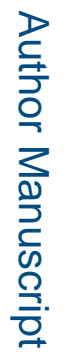

Arch Womens Ment Health. Author manuscript; available in PMC 2016 April 01. 


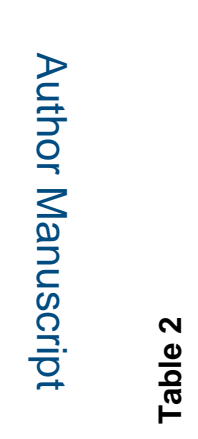

\begin{tabular}{|c|c|c|c|c|c|c|c|}
\hline 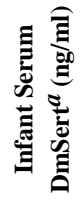 & $\mid \begin{array}{c}0 \\
\omega \\
+1 \\
\tilde{\Xi} \\
\sum^{2} \\
z\end{array}$ & $\begin{array}{l}\vec{\partial} \\
\dot{m} \\
+1 \\
\dot{m}\end{array} \mid$ & $\begin{array}{l}\stackrel{\tilde{i}}{+} \\
+1 \\
\stackrel{-}{\vec{j}}\end{array}$ & $\begin{array}{l}0 \\
0 \\
0 \\
+1 \\
0 \\
i\end{array}$ & $\mid \begin{array}{l}n \\
n \\
+1 \\
\hat{i} \\
\text { in }\end{array}$ & $\begin{array}{l}\stackrel{+}{.} \\
0 \\
0 \\
+1 \\
\stackrel{+}{=} \\
=\end{array}$ & $\begin{array}{l}+ \\
i \\
+1 \\
+ \\
\dot{r}\end{array}$ \\
\hline 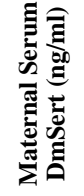 & 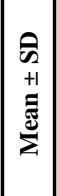 & $\begin{array}{l}0 \\
\dot{b} \\
+1 \\
+1 \\
\hat{j} \\
0\end{array}$ & $\begin{array}{l}m \\
2 \\
+1 \\
\infty \\
=\end{array}$ & 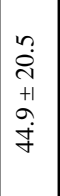 & $\begin{array}{l}n \\
0 \\
0 \\
+1 \\
y \\
\vdots \\
2\end{array}$ & 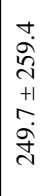 & 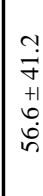 \\
\hline
\end{tabular}

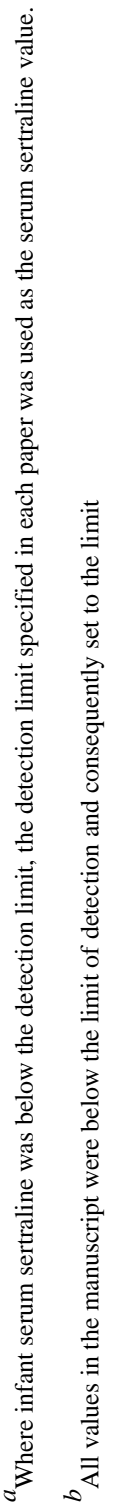

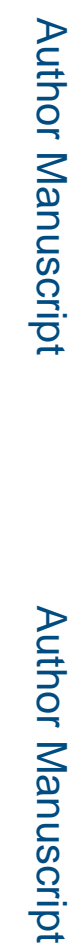

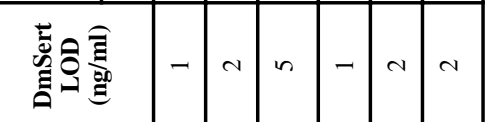

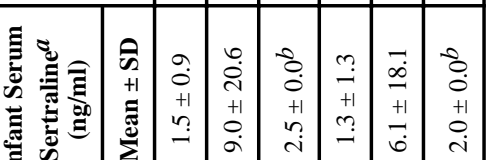

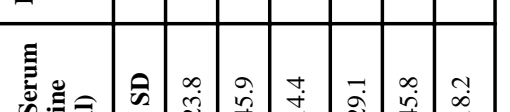

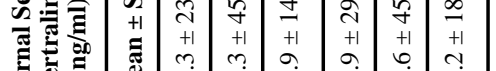

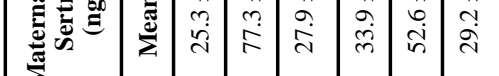

\begin{tabular}{|c|c|c|c|c|c|c|}
\hline 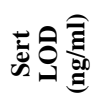 & - & $\sim$ & $\stackrel{n}{i}$ & -1 & $\mathrm{~N}$ & $a$ \\
\hline z & $=$ & $a$ & $=$ & নे & ส & $\stackrel{2}{ }$ \\
\hline$\stackrel{z}{E_{0}}$ & 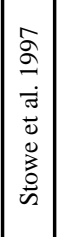 & 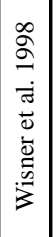 & 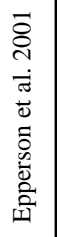 & 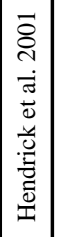 & 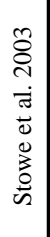 & 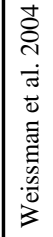 \\
\hline
\end{tabular}




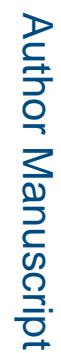

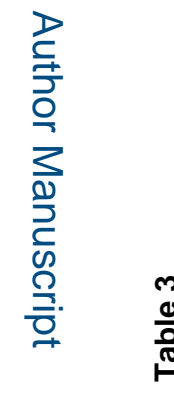

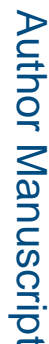

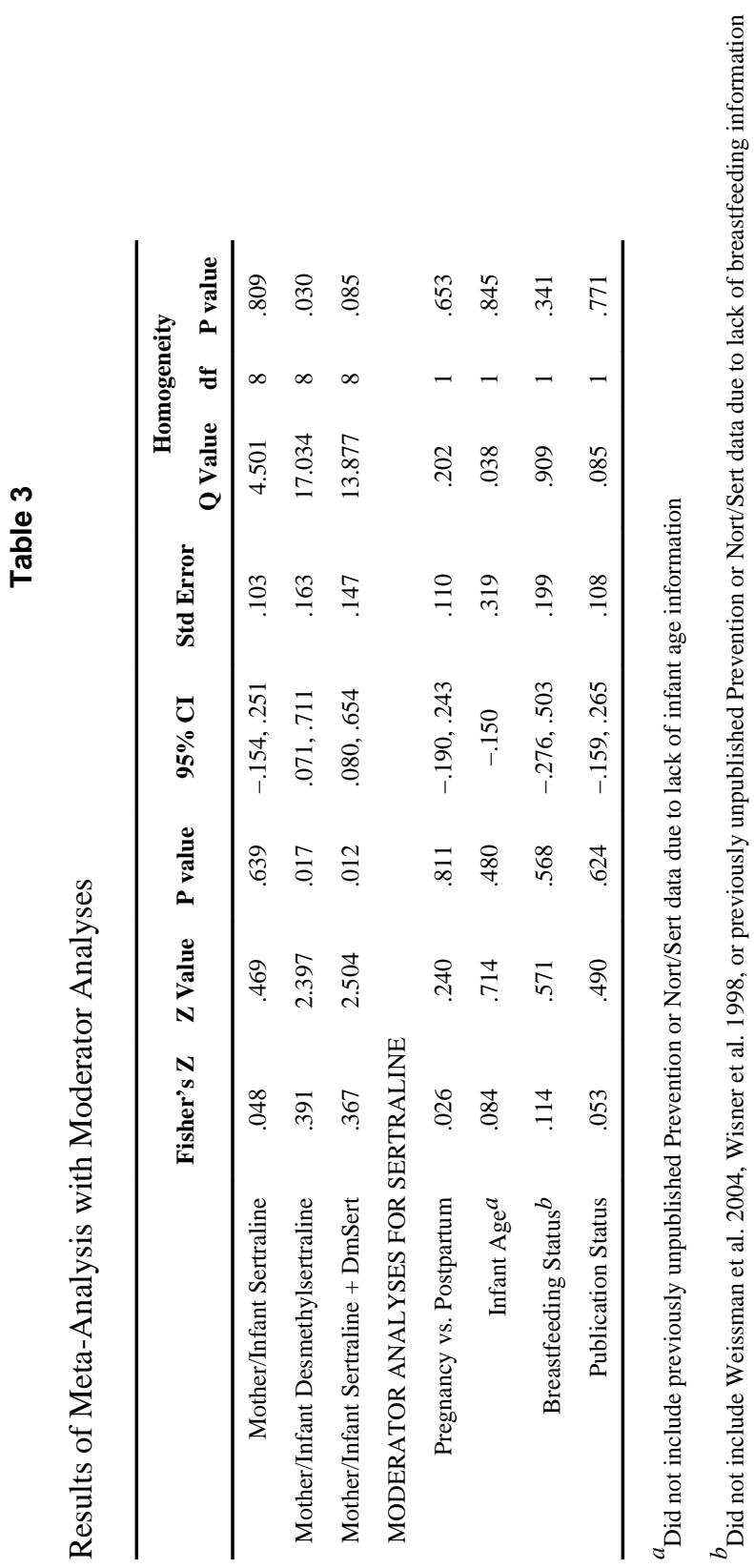

Arch Womens Ment Health. Author manuscript; available in PMC 2016 April 01. 